5. Loss of feeling of pain or pinching; diminished sensibility to cold and heat, and to touch. Fracture of the seventh cervical vertebra, and softening of the spinal cord. (Ollivier, loc. cit., vol. i., p. 287.)

Most unfortunately, medical men usually neglect noticing the state of the various kinds of sensibility in cases of disease of the spinal cord. It is interesting, therefore, to collect the cases in which there is a mention of some, if not all, the kinds of sensibility. We give here a list of some of such cases.

6. Return of general sensibility of the skin (probably to contact and pain), and of muscular sense. Local destruction of posterior columns. (See Case 8, Lecture V.)

7. All kinds of sensibility persisting. Alteration of the posterior columns. (Case 9, Lecture V.)

8. Scratching, pricking, and pinching the skin were felt. Alteration of the posterior columns. (Case 14, Lecture V.)

9. Touch and painful impressions acutely felt, as also any change of temperature. Alteration of the posterior columns, and slightly of the rest of the cord. (Case 16 , Lecture V.)

10. All kinds of sensibility persisting. The whole of the white substance of the cord altered. (Case 22, Lecture VI.)

We might add to this list of facts many cases of alteration of the anterior or of the lateral columns of the spinal cord in which it has been noted that touch, heat and cold, and painful impressions, have continued to be felt. But it is unnecessary to mention cases so frequent as those are.

Now, on the other hand, in some of the cases of alteration of the grey matter that we have related in the preceding lectures, it has been noted that there was a loss of the various kinds of sensibility.

From this review of facts, it results that what we have said of sensibility generally, may be applied to its various kinds. The grey matter is the principal channel of the various sensitive impressions, and the posterior columns are not the channels for any kind of these impressions. Therefore, as a means of diagnosis of the place where an alteration exists in the spinal cord, any kind of anæsthesia cannot be considered as a symptom of alteration of the posterior columns; while, on the contrary, the loss of one kind of sensibility, another kind remaining, may serve, as we will show hereafter, as a means of diagnosis of an alteration of the grey matter of the spinal cord.

(To be continued.)

\section{REPORT ON ANAESTHESIA.}

By R. M. GLOVER, M.D., F.R.S. EDIN., L.R.C.P. LOXD.

"Summ cuique tributo."

No. I.

Divisions of the Report-1st. History of ancestluesia up to the time when the occasional danger of ancesthetic agents became established.-Pe-discontry of ancesthesia in modern times. Nitrous oxide, etler. - Fatal case of etherization.--Attempts to find a substitute. - Professor Simpson and chloiroform.Dr. Glover's axperimeints on chloroform.-History of chloroform. - Physiological properties first accurately stated by $D r$. Glover.-Chloric ether-A nosthetic effects on animals first demonstrater by Fuatishs. - Dr. Simpson's application of it in practice.

REcexr futal cases having again called public attention and that of the profession to the danger attending the use of chloro form, and the eccentric character, if I may use such a phrase, of the fatal result, i* I have thought right to use the occasion to review some facts, not generally known, connected with the early history of chloroforn, which throw some light upon the action of the substance, before stating my views of its modus operandi, and what appears to me the best mode of preventing its occasionally calamitous effects.

$I$ intend to divide this report into three parts. In the first I shall trace the history of ancsthesia up to the time of the first fatal cases, when the profession was in possession of facts which

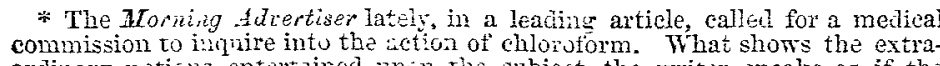
commission to ningire intu the action of chloruform. What shows the extrat public heard tor the first time is the danger of chloroform. So far is thi

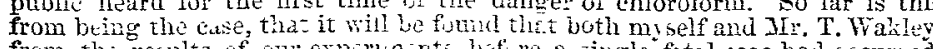
from the results of our experincrts, lafure a sirgle fatal case had coenred could leare no doubt that the new class of amæsthetic agents was capable of relieving pain in surgical operations, in midwifery, and so forth, but that their use in certain cases was attended with great risk. In the second part I shall enumerate and briefly analyze all the fatal cases from those early ones described in the first part up to the present time, with the view of arriving, if possible, at the cause or causes of death; and in the third part I shall give what I consider the real modus operandi of the agents, and my views concerning the best means of averting danger, and the remedial measures to be employed where death is threatened.

1. The history of almost all inventions displays a somewhat similar character. There is nothing new under the sun. Anæsthesia was not unknown to the ancients. Pliny and Dioscorides distinctly state that the root of the mandrake has the power of throwing patients into such a deep sleep as to render them insensible to the pain of surgical operations. Towards the close of the seventeenth century a secret agent was employed to render a King of Poland insensible during the removal of a portion of his foot. But the practice of anæsthesia had completely passed away. The first person to propose its renewal in our time was Sir Humphry Dary. He says, in his remarks on nitrous oxide: "As nitrous oxide, in its extensive operation, appears capable of destroying physical pain, it may probably be used with advantage in surgical operations, in which no great effusion of blood takes place." And it was with nitrous oxide that, in 1814, Mr. Wells, of Connecticut, first succeeded in removing teeth without pain, and suggested the use of this gas in surgical operations. " What is important is this: during the reion of ether there were a few cases where ether was supposed not to be disconnected with the cause of death. There was also the case of Mrs. Parkinson, who died at Grantham on the 9th of March, 1847, two days after the removal of a tumour, while she was in a state of partial anæsthesia; and although the post-mortem appearances were anything but decided, the jury returned a verdict of " died from the effects of ether." The only case, however, in which ether seems to have produced death with the rapidity in which the same result has unfortunately so often attended the use of chloroform, is one which occurred at Auxerre, in France, in August, 1847. A man, aged fifty-five, operated on for cancer, was rendered quite insensible by ether, when suddenly, just as the operation had commenced, the face turned violet and then livid; the pulse became low, and then ceased to beat, and he was found to be quite dead in ten minutes from the commencement of the inhalation. The post-mortem appearances were chiefly congestion of the posterior portions of the lungs, with frothy macus in the air-tubes, which were stained of a dark colour, and darkness and fluidity of the blood. These appearances closely resemble, as will be seen, what has been often found in chloroform-poisoning.

While considerable discussion was being carried on concerning the merits of etherization, and especially its application to midwifery, all at once an immense sensation was excited by the announcement that a new remedy of superior power had been discovered by Professor Simpson. Many other ethers had been experimented on before this besides sulphuric ether-as muriatic, nitric, acetic, and formic ethers. There can be no doubt that a substance of no very certain composition, but containing chloroform, had been used on the recommendation of $\mathrm{Mr}$. Jacob Bell, in the spring of 1847, and that Flourens had used the vapour of chloroform on animals about the same time, as we shall immediately see. Dr. Simpson's first publication was dated November 15th, 1847. Long previously, I had published an elaborate series of experiments on animals with chloroform and its allied bodies, at a time when their very names were almost unknown, and stated their physiological properties with great accuracy; and this leads me to speak of chloroform and its previous history before Dr. Simpson's application of it to practice.

According to some historical references given by the late Dr. Pereira, in the Phamaceutical Joumal, chloroform was first obtained by Mr. Samuel Guthrie, of Sacket's Harbour, New Yor's, by distilling a mixture of chloride of lime and alcohol. He supposed, however, that he had only obtained chloride of olefiant gas (the Dutch liquid), or muriatic ether, by a new process. He communicated his observation to Silliman's Jounal for January, 1S32, under the title of "A New Mode of Preparing a Sujitous Solution of Chloric Ether." He said that he hal used the prodnct for six months occasionally up to the point of intoxication; had

* The history of the introdiation of ether, and the rival claims of Hessrs.

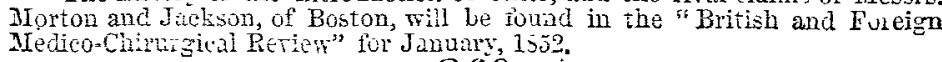


found it very grateful, producing a flow of spirits and inclination to loquacity, without leaving behind it the depression consequent upon the use of ardent spirits; and he recommended it, mixed with an equal quantity of water, as a safe, quick, energetic, and palatable stimnlus. Mr. G. Black, of Bolton, in the Medical Gazette of September, 1833, published an article on the same substance, headed "Chloric Ether: New Remedy in Spasmodic Asthma." He calls the ether a solution of chloride of carbon in alcohol, "brought into nse by our American brethren," and considers it a light and diffusive cordial likely to be of use in spasmodic and adynamic states, and recommends it in doses of half a drachm. About the same time as Mr. Guthrie, M. Soubeiran distilled a mixture of alcohol and chloride of lime, and termed the product bichloric ether. Next, Liebig examined it, and, by some oversight, not finding any liydrogen, termed it chloride of carbon. Dumas, in 1534, first discovered its true chemical nature, and called it chloroform; while Liebig termed it perchloride of formyle."

I was the first to describe correctly the physiological properties of chloroform and its analogous bodies, and to assign them their true place; and my experiments have a direct bearing upon the question as to the mode in which chloroform acts. These experiments were first published in the Edimlurgh $M e$ dical and Surgicul Joumal for Oct. 1842, and were reprinted in The LAveri for Feb. 26th, 1848, also in the Medical Gazctte. They are to be found as part of a work on the physiologieal and medicinal properties of the whole group of chlorine, bromine, and iodine, and their componnds, and the relations which these bear to the chemical properties of the same. My great object was to test the truth of the grent law,--viz., that the chemical and physiological properties of bodies are closely related; and, taking up for experiment the least-known of the remarkable group which formed the subject of my paper, I was particulirly led to test the properties of chloroform and its analogous bodies, then almost unknown. The chapter is headed, "Physioloyical Properties of Chloride and Bromide of Olefiant Gas, of Chloroform, Bromoform, and Iodoform." $\nmid$ The following are the general conclusions arrived at:-

"Remarks. - Great resemblance exists amongst the properties of this class of bodies, which appear to form a new order of poisonous substances, uniting in themselves physiological properties which are not found united in any other class of poisons. The distinguishing characteristics are-first, the remarkable power which they possess of obstructing the pulmonic circulation, whether they are injected into the veins or introduced into the stomach; then the action on the spinal cord, and afterwards on the brain; and, lastly, the corrosive and irritant action exercised on the stomach. In the case where chloroform was injected into the carotid, death appears to have been produced by the loss of nervous power from the direct action of the poison on the brain. This effect might be accounted for by the obstruction thus induced to the flow of blood through the capillaries of the organ. The mechanical properties of this class of bodies may particularly fit them for obstructing the circulation through the lungs. It was shown, for instance, that when injected into the jugular, their smell is almost immediately perceptible in the expired air; so that the vapour getting into the air-cells may place the blood much in contact with the substance. The action on the spinal cord is very different from that of strychnia, to which my friend Dr. Cogswell compared it in the case of iodoform. Strychnia destroys the influence of the will over the muscles, but appears to excite the spinal cord, which loses its sensibility under the action of this class of poisons. The blackening of the mucous membrane of the stomach which these substances produce is another curious property. This effect appears to be compounded of the corrosive and irritant action of the poison, its effects on the colouring matter of the blood, and that congestion of dark blood found in the stomach in certain cases of coma. Where the poison was introduced directly into the circulation, we had the heart's action put a stop to, and its irrita. bility destroyed when the dose was large. In other cases a smaller dose caused obstruction to the flow of blood through the lungs, while the heart's action continued; and in one case this obstruction was shown by the hæmadynamometer. In that case the pressure in the arterial system was diminished, but the heart's action continued."

* Chloroform, bromoform, and iodoform are analogous to formic acid, each of these bodies having three equivalents of chlorine, bromine, iodine, oxygen, added to the radical formyle, which is $\mathrm{C}_{2} \mathrm{H}$. Thus we have respectively $\mathrm{C}_{2} \mathrm{H} \mathrm{ChJ}_{3}, \mathrm{C}_{2} \mathrm{H} \mathrm{Br}_{3}, \mathrm{C}_{2} \mathrm{H}, \mathrm{I}_{3}$, and $\mathrm{C}_{2} \mathrm{H} \mathrm{O}_{3}$

$t$ The general rescmblance of the group is first pointed out: all may be used as 'næsthetic agents except iodoform, on account of its solidity. Chlo roform is then selected as the most remarkable, as a specimen of the rest.
I then remark on the great power possessed by the whole class of permeating the tissues.

It must be remembered that my experiments were performed at a time when nothing was known of the physiological properties of this class of bodies, except the triling facts previously referred to; and even now the general correctness of my conclusions must be granted. I pointed out the fact of the insensibility of the animals when pricked and pinched, but I never thought of applying the facts I had observed to the prevention of pain in surgical operations; indeed, no one thought of anresthesia at the time.

The next great fact in the history of chloroform is, substantially, the first application of its vapour as an anæesthetic agent; for the chloric ether of Mr. Bell was at most only a mixture containing chloroform, and was not administered on account of the chloroform. On the 8th of March, 1847, M. Flourens, in a communication to the French Academy of Sciences, related some experiments made by him on animals with the vapour of chloroform. "It was especially by the effects of muriatic ether that he was led to try the new body known by the name of chloroform. At the end of some minutes - of six in a first experiment, and of four in two others-the animals submitted to the operation were distinctly etherized. The spinal cord was then exposed. The posterior roots of the spinal nerves were found to be insensible; of five anterior roots only two preserved their motive power, the three others had lost it. Thus it is incontestable that the discovery of the anæsthetic properties of chloroform is due to a French philosopher.

Unfortunately, he confined his operations to animals." *

Nothing more of a public character took place with regard to chloroform till, on the 10ih of November, 1847, Dr. Simpson presented his first results at a meeting of the Medico-Chirurgical Society of Edinburgh. What these were it is unnecessaly to repeat here. Suffice it to state, that to Dr. Simpson belongs the sole and entire merit of first applying the vapour of pure chloroform as an anæsthetic agent in the izuman subject. $t^{+}$

(To be continued.)

ON

\section{TWO CASES OF ULCERATION OF THE STOMACH IN BOYS.}

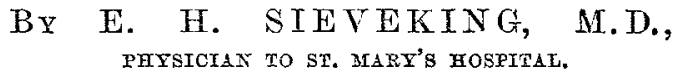

THE great rarity of ulcers of the stomach in early life appears to justify my putting on record the following two cases, in which, although recovery took place, and therefore the positive confirmation of the diagnosis is wanting, the complex of symptoms scarcely can leave a doubt as to its correctness. The liability to ulcer of the stomach, as Dr. Brintont has well shown, "rises from what is almost a zero at the age of ten to a high rate, which it maintains through the period of middle life, at the end of which period it again ascends, to reach its maximum at the extreme age of ninety." The subjects of the two cases I am about to relate were the sons of a man who himself was consumptive, and whose sisters were also phthisical;

* Bouisson: Traité de la Méthode Anæsthétique appliquée à la Chirurgie et aux différentes branches de l'Art de Guérir, p. 77 .

+ The following, from a pamphlet by Mr. Waldie, of Liverpool, (1847, is interesting:- "To the best of my knowledge, from the result of many inquiries it seems to have been introduced into this conntry, as a medicinal agent, firs in Liverpool, where, indeed, in the form of a spirituons solution, it has been more known than in any other part of the country, and from which, $I$ believe, the knowledge of its therapeutic properties extended. About the year 1838 or 1839 , a prescription was brought to Apothecaries' Hall, Conduit-street, one ingredient of which was chloric ether. No substance being known there of that name having the properties of that with which the mixture had been previously prepared, $\mathrm{D}_{\mathrm{r}}$. Brett, then the Company's chemist, in investigating the subject, found in the United States Dispensatory the formula of its preparation, and prepared some." Mr. Waldie states that the properties of the substance pleased some of the medical men, but the preparation was found of variable strength. He separated the chloroform, and dissolved it in a uniform quantity of pure spirit. He goes on to say that the vapour of this so-called ehloric ether was used for anesthetic purposes, "either in February or March last" (Mr. Bell). 'Then, "when in Scotland, in October last, Dr. Simpson introduced the subject to me, inquiring if I knew of anything likely to answer. Chloric ether was mentioned during the conversation, and, being well acquainted with its composition, and with the volatility, agreeable flavour, and medicinal properties of chloroform, I advised him to try it ;" which accordingly Professor Simpson did.

\pm On the Pathology, Symptoms, and Treatment of Uleer of the Stomach. By William Brinton, M.D. London, 1857. p. 9. 